\title{
Convenient conversion of calcium carbonate to hydroxyapatite at ambient pressure
}

\author{
Cédric Verwilghen ${ }^{\mathrm{a}}$, Mouna Chkir ${ }^{\mathrm{a}}$, Sébastien Rio ${ }^{\mathrm{a}}$, Ange Nzihou ${ }^{\mathrm{a}}$, Patrick Sharrock ${ }^{\mathrm{b}, *}$, Guy Depelsenaire $^{\mathrm{c}}$ \\ ${ }^{a}$ RAPSODEE Research Centre, UMR CNRS 2392, Ecole des Mines d'Albi-Carmaux, 81013 Albi, France \\ ${ }^{\mathrm{b}}$ LERISM department of Chemistry, Paul Sabatier University, 81104, Castres, France \\ c Solvay SA, B-1050 Brussels, Belgium
}

\section{A B S T R A C T}

The synthesis of hydroxyapatite is described starting from calcium carbonate and monoammoniumphosphate in stoichiometric amounts. The novel aspect concerns the reaction conditions which are simple mixing in water at ambient pressure and $60{ }^{\circ} \mathrm{C}$. The calcium carbonate solid phase slowly evolves $\mathrm{CO}_{2}$ gas and buffers the solution at a $\mathrm{pH}$ value of 8.05 where hydroxyapatite precipitates. The main advantages of this reaction pathway are the absence of nitrate salts, the availability of the starting materials and the purity of the final product.

Keywords:

Calcium carbonate

Calcium orthophosphate

Maturation

Hydroxyapatite

\section{Introduction}

Hydroxyapatite (HA) synthesis is usually a laborious endeavor. HA is used in the manufacture of biomaterials and also for environmental applications [1]. One of the first methods reported involved hydrothermal conversion of coral. The most standard procedure is that described in Inorganic Synthesis and known as the double decomposition procedure because calcium nitrate dissolves and reacts with ammonium phosphate to yield the calcium phosphate and ammonium nitrate [2]. This requires a meticulous washing step to remove the ammonium nitrate by-product and long filtration times because of the gel-like nature of the precipitate which is accentuated at the basic $\mathrm{pH}$ values used. Ammonium nitrate remnants are usually eliminated by sublimation during subsequent thermal treatment.

A simple approach is to neutralize a lime solution with phosphoric acid in proper amounts. However lime is not very soluble in water and large volumes are required to precipitate HA from solution. If a suspension of calcium hydroxide is reacted with phosphoric acid, the calcium phosphate precipitate covers the lime particles, slows the reaction or eventually leads to the formation of HA contaminated with unreacted lime and with brushite, $\mathrm{CaHPO}_{4}$.

Other methods have been reported which all suffer from either long reaction times or the use of unusual precursors [3-11]. The biomimetic synthesis is interesting but yields are low [12]. The various known methods have been reviewed [13-17]. The more recent and unusual methods describe the use of magnetic fields or microwave

\footnotetext{
* Corresponding author.

E-mail addresses: patrick.sharrock@iut-tlse3.fr, patrick.sharrock@gmail.com (P. Sharrock).
}

heating $[18,19]$, ultrasonic precipitation [20] or template synthesis [21].

When pure stoichiometric HA is sought, heating or long maturation times are required to transform the initial tricalcium phosphate (TCP) precipitate into the thermodynamic HA product [22]. X-ray diffraction analysis of the calcined product will tell how much TCP is found in the HA [23]. The slow step may be described as reaction (1): the consumption of lime can be followed by the so-called pH drop method and illustrates the formation of HA [24].

$3\left[\mathrm{Ca}_{3}\left(\mathrm{PO}_{4}\right)_{2}\right]+\mathrm{Ca}(\mathrm{OH})_{2} \rightarrow \mathrm{Ca}_{10}\left(\mathrm{PO}_{4}\right)_{6}(\mathrm{OH})_{2}$

Once the product is sintered, it is practically impossible to separate the TCP from the HA. This may be a handicap if stoichiometric HA is required for medical grade plasma sprayed coatings. Only the most dense and pure crystallites resist thermal decomposition during spraying. It is therefore of interest to have a reproducible method of stoichiometric HA synthesis based on readily available starting materials of adequate purity.

We now report the convenient one step synthesis of HA starting from calcium carbonate and monoammoniumphosphate at ambient pressure.

\section{Experimental}

Calcium carbonate was a reagent grade powder from Aldrich and used as received. Ammonium phosphate crystals were from Hydro Azote Spécialités (Belgium) and had $61 \% \mathrm{P}_{2} \mathrm{O}_{5} .50 \mathrm{ml}$ of a suspension containing $20.31 \mathrm{~g}$ of calcium carbonate were was introduced into a $250 \mathrm{ml}$ beaker containing $13.89 \mathrm{~g}$ of ammonium phosphate dissolved in $50 \mathrm{ml}$ of distilled water. The suspension was stirred at a temperature 
a

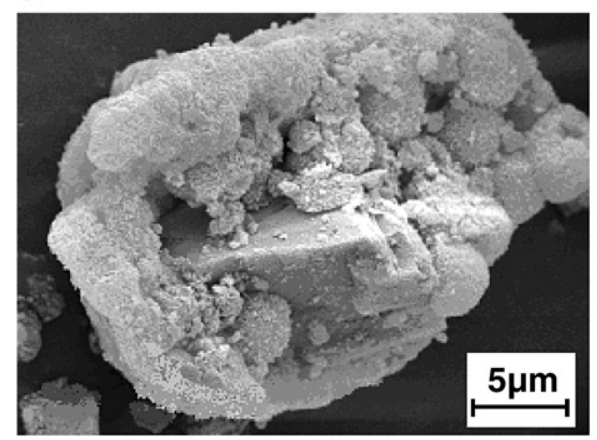

C

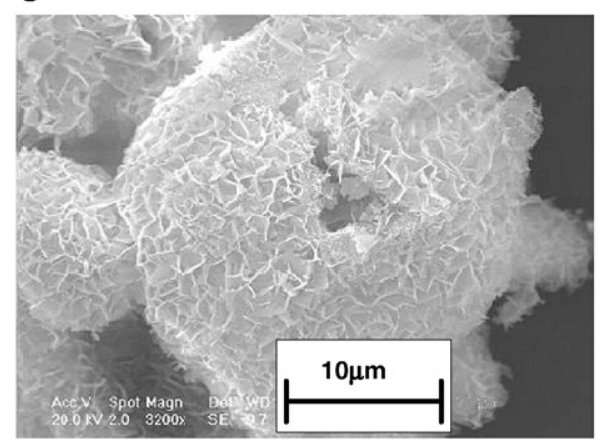

b

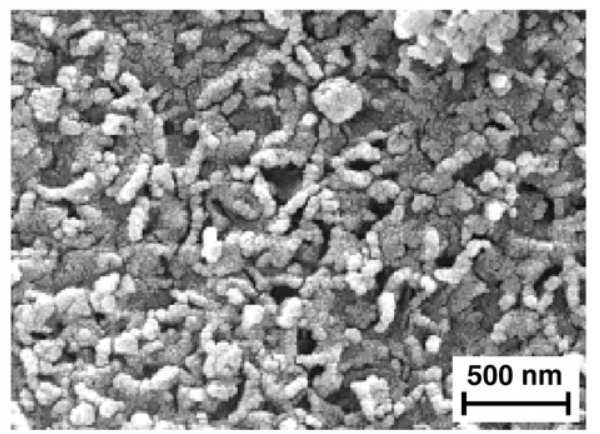

d

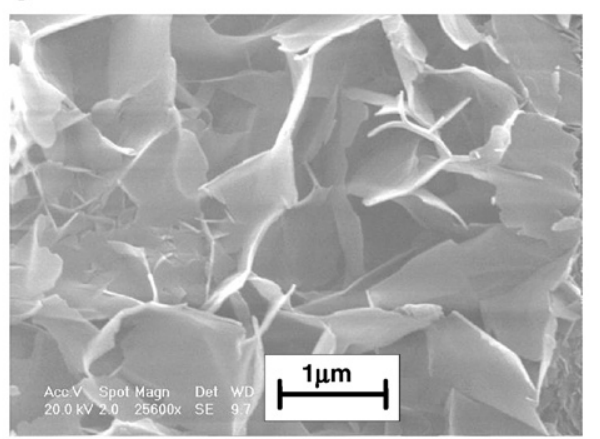

Fig. 1. SEM image of the product formed during the course of the transformation of calcium carbonate to calcium phosphate. Reaction product after 30 min (a and b), after $2 \mathrm{~h}$ (c and $\mathrm{d})$.

of $60{ }^{\circ} \mathrm{C}$ under air atmosphere. Immediately, the evolution of $\mathrm{CO}_{2}$ gas could be observed. The reaction was continued for $72 \mathrm{~h}$.

The white solids collected by filtration were oven dried to yield a fine powder. The product was rinsed with distilled water to dissolve any unreacted phosphate. The final yield was near $90 \%$ based on the ammonium phosphate used.

Infrared spectra were recorded in $\mathrm{KBr}$ pellets with an ATI Mattson Genesis Series FTIR spectrometer and X-ray powder diffraction patterns were recorded using $\mathrm{CuK} \alpha$ radiation and a Philips XPert spectrometer. A Philips XL30 ESEM FEG was used for microscopic observations. The specific surface area (SSA) was measured by the BET method (5 points) using nitrogen adsorption at $77 \mathrm{~K}$ with a Micromeritics Vacrep 061. Prior to analysis, samples were degassed under reduced pressure (0.05-0.1 mbar).

\section{Results and discussion}

Calcium carbonate has a low hardness value of 3 Mohs and is easily ground to a fine powder which yields homogeneous water suspensions under adequate stirring. When any amount of ammonium dihydrogen phosphate is introduced into the suspension, it dissolves readily and the $\mathrm{pH}$ gradually increases from the starting value of $\mathrm{pH}$ 4.8 to the final value of $\mathrm{pH}$ 8.5. This $\mathrm{pH}$ value corresponds to the formation of an ammonium carbonate buffer. Accordingly $\mathrm{CO}_{2}$ gas is evolved, and indeed bubbles were observed which escaped at an accelerated pace when the suspension was heated. Progressively, the viscosity of the suspension increased, the solid carbonate was consumed, and a calcium phosphate gel resulted. The reaction could be described by the overall reaction (2). Little by-products are formed. $\mathrm{CO}_{2}$ evolves.

$$
\begin{aligned}
& 10 \mathrm{CaCO}_{3}+6 \mathrm{NH}_{4}\left(\mathrm{H}_{2} \mathrm{PO}_{4}\right)+2 \mathrm{H}_{2} 0 \rightarrow \mathrm{Ca}_{10}\left(\mathrm{PO}_{4}\right)_{6}(\mathrm{OH})_{2} \\
& \quad+3\left(\mathrm{NH}_{4}\right)_{2} \mathrm{CO}_{3}+7 \mathrm{H}_{2} \mathrm{CO}_{3} .
\end{aligned}
$$

Fig. 1 illustrates the formation of the amorphous calcium phosphate precipitate on the surface of calcium carbonate crystallites.
Besides the observation of the formation of a coating on the surface of the starting material, many small particulates were found detached into the suspension, as confirmed by laser diffusion analysis. The calcium carbonate had an average particle diameter of $45 \mu \mathrm{m}$ while

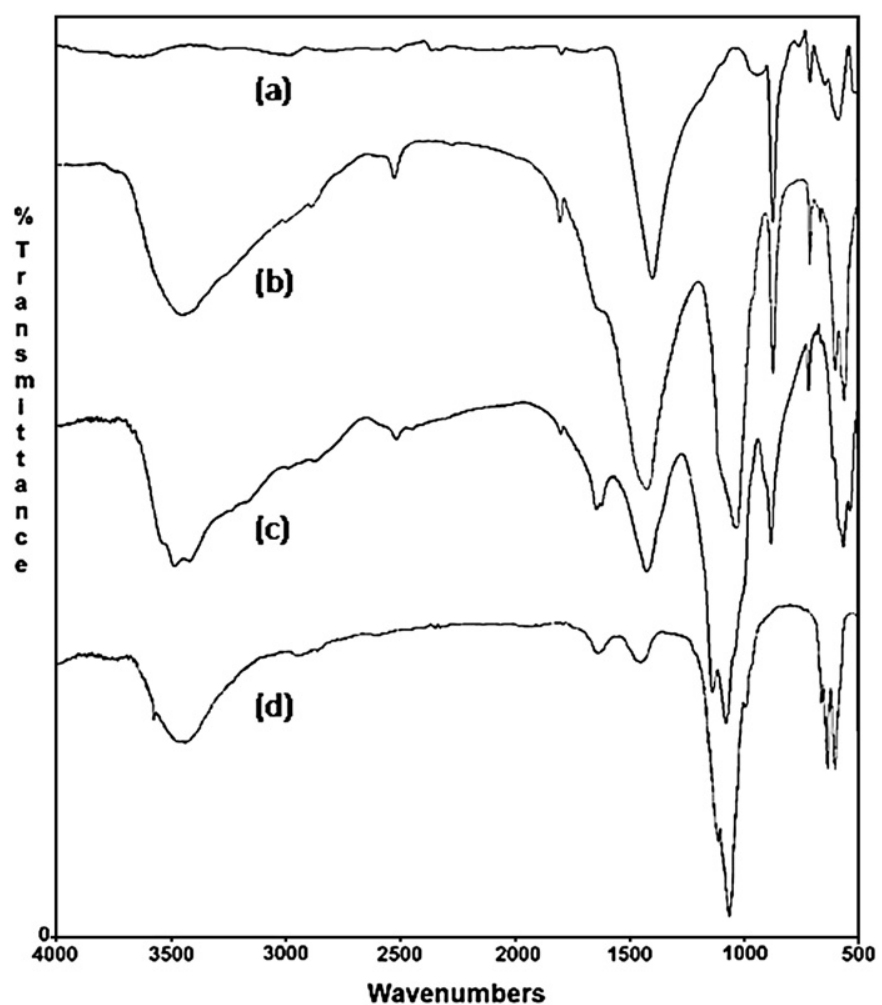

Fig. 2. IR spectra of starting product $\mathrm{CaCO}_{3}$ (a), reaction product after $30 \mathrm{~min}$ (b), after $2 \mathrm{~h}$ (c) and after $72 \mathrm{~h}$ (c). 


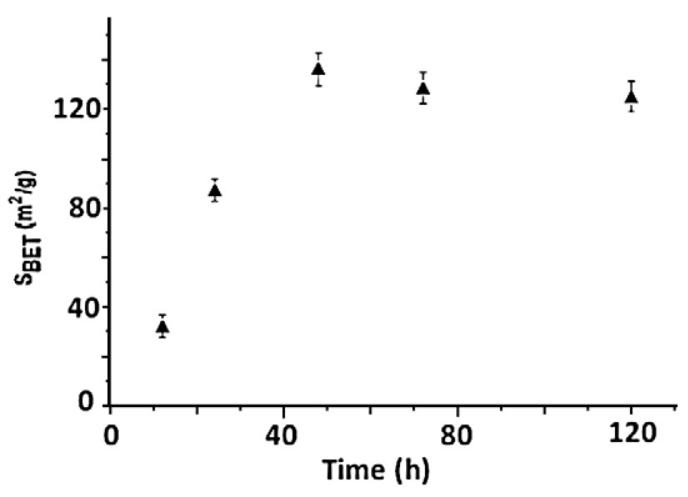

Fig. 3. Specific surface area of the dried reaction products as a function of reaction time.

the final suspension showed smaller particles with an average diameter of $9 \mu \mathrm{m}$.

The evolution of the transformation could be followed by infrared spectroscopy of the solid phase, as illustrated in Fig. 2.

Clearly, the carbonate band at $1400 \mathrm{~cm}^{-1}$ was progressively replaced by a phosphate band at $1050 \mathrm{~cm}^{-1}$. If the reaction mixture was filtered before completion of the reaction, then unreacted soluble phosphate was removed and excess calcium carbonate remained as an impurity in the solid phase. Following the first hours of reaction a gel was formed, and several $\mathrm{OH}$ stretching bands appeared in the IR spectrum around $3500 \mathrm{~cm}^{-1}$. After a 72 hours reaction period, very little calcium carbonates remained.

X-ray diffraction studies confirmed the formation of an amorphous calcium phosphate precursor, as evidenced by a low intensity and broad line-width peak observed at $2.8 \AA$, next to a calcium carbonate diffraction peak at $3 \AA$, which progressively decreased in intensity as the reaction moved forward. If the intermediate product was calcined, it showed diffraction patterns of both HA and lime (strong peak at $2.4 \AA$ ), while the water washed solids only showed HA diffractions following the dissolution of lime.

The measured specific surface areas of the reaction products increased as the gel phase formed, and leveled at a value near $130 \mathrm{~m}^{2} /$ $\mathrm{g}$, as illustrated in Fig. 3. Aging the solids in a sealed tube caused the specific surface area of the final product to slowly decrease by nearly $20 \%$ over a one year period. Such results are in agreement with previous investigations on high specific surface area HA [25].

To explain why HA formed during the low temperature and ambient pressure reaction described herein, one must recall the following facts: Calcium carbonate is unstable under acidic $\mathrm{pH}$ conditions, but reaction with phosphoric acid produces poorly soluble monetite coatings which block further reaction. Furthermore, HA is formed at basic $\mathrm{pH}$ values, where calcium carbonate is stable and no reaction is expected unless the system is heated under pressure like in the hydrothermal process [26]. We hypothesize that at ambient pressure, hydrogenophosphate groups first adsorbed on the carbonate surface, and then were deprotonated to form calcium orthophosphate, releasing the carbonate anions into the solution. The ammonium carbonate buffer then formed which stabilized the $\mathrm{pH}$ to a value where HA was the most stable calcium phosphate phase. Gentle heating of the solution accelerated the $\mathrm{CO}_{2}$ degassing and pushed reaction 2 towards the formation of $\mathrm{HA}$ and consumption of carbonate. The reaction proceeded at an appreciable rate with vigorous stirring. Monoammonium phosphate could be replaced by monosodium or potassium phosphate as well.

Previous work centered on the isolation of carbonated HA has centered on the use of soluble carbonates to modify the synthetic conditions resulting in carbonate substituted HA. However, this type of HA lost carbonates when calcined at high temperatures [5].

In related work, it was proposed that phosphate effectively adsorbed onto the surface of the calcium carbonate species [27].
Calcite has been used to remove phosphate from aqueous solutions effectively [28]. P. Piantone et al. [29] have examined the reaction of phosphate with various mineral species and described the usual sequence of events when calcium ions react in solution with phosphate: the first mineral species to precipitate is $\mathrm{CaHPO}_{4} \cdot 2 \mathrm{H}_{2} \mathrm{O}$ (brushite) followed by $\mathrm{Ca}_{3}\left(\mathrm{PO}_{4}\right)_{2}$ (whitlockite), $\mathrm{Ca}_{4} \mathrm{H}\left(\mathrm{PO}_{4}\right)_{3} \cdot 5 \mathrm{H}_{2} \mathrm{O}$ (octacalcium phosphate) and finally $\mathrm{Ca}_{5}\left(\mathrm{PO}_{4}\right) 3 \mathrm{OH}$ (hydroxylapatite). The theoretical phase diagram describing the stable minerals in $\mathrm{pH}$ vs. total $\mathrm{CO}_{3}$ coordinates showed that when the $\mathrm{CO}_{2}$ gas partial pressure was near atmospheric pressure there was a narrow $\mathrm{pH}$ range between 6 and 9.5 where calcite could be converted to apatite [29]. Coverage of calcite crystals with carbonated apatite has been reported in Na-K phosphate solution of $\mathrm{pH} 7.4$ [30].

\section{Conclusion}

Interest in this new synthetic pathway stems from the absence of nitrate by-products. Tedious washing procedures are not required to eliminate nitrate salts. There is no need for calcinations of the end product if large surface areas are needed. The solid suspension conditions yields an easily filtered suspension, contrary to the other synthesis methods known. The reaction and maturation times depend on the reaction temperature, but this can be done at ambient pressure in open vessels. An added advantage is that the starting materials calcium carbonate and ammonium phosphate can be found in very pure form and thus the resulting HA is of high quality.

\section{Acknowledgement}

We gratefully acknowledge the financial support of Solvay HSE (Belgium)

\section{References}

[1] B. Bournonville, A. Nzihou, P. Sharrock, G. Depelsenaire, Trans. IChemE, PartB, Proc. Safe. and Environ. Protec. 84 (B2) (2006) 117.

[2] E. Hayek, H. Neweseley, Inorg. Synth. 7 (1963) 63.

[3] M. Jarcho, C.H. Bolen, M.B. Thomas, J. Bobick, J.F. Kay, R.H. Doremus, J. Mater. Sci. 11 (1976) 2027.

[4] V. Jokanović, D. Izvonar, M.D. Dramicanin, B. Jokanović, V. Živojinović, D. Marković, B. Dačić, J. Mater. Sci. Mater. Med. 17 (2006) 539.

[5] J. Barralet, S. Best, W. Bonfield, J. Biomed. Mater. Res. 41 (1998) 79.

[6] R. Murugan, S. Ramakrishna, K. Panduranga Rao, Mater. Lett. 60 (2006) 2844.

[7] Y. Wang, S. Zhang, K. Wei, N. Zhao, J. Chen, X. Wang, Mater. Lett. 60 (2006) 1484

[8] Y. Wang, J. Chen, K. Wei, S. Zhang, X. Wang, Mater. Lett. 60 (2006) 3227.

[9] M.R. Saeri, A. Afshar, M. Ghorbani, N. Ehsani, C.C. Sorrell, Mater. Lett. 57 (2003) 4064 .

[10] Y. Han, S. Li, X. Wang, L. Jia, J. He, Mater. Res. Bull. 42 (2007) 1169.

[11] J.K. Khongwar, K.R. Kannan, G. Buvaneswari, Mater. Res. Bull. 43 (2008) 418

[12] S. Liao, F. Watari, G. Xu, M. Ngiam, S. Ramakrishna and C.K. Chan, Mater. Lett. 61 (2007) 3624

[13] A.A. Chaudhry, S. Haque, S. Kellici, P. Boldrin, I. Rehman, F.A. Khalid, J.A. Darr, Chem. Commun. (2006) 2286.

[14] W. Feng, L. Mu-sen, L. Yu-peng, Q. Yong-xin, Mater. Lett. 59 (2005) 916

[15] G. González, A. Sagarzazu, R. Villalba, Mater. Res. Bull. 41 (2006) 1902.

[16] I. Bogdanoviciene, A. Beganskiene, K. Tõnsuaadu, J. Glaser, H.J. Meyer, A. Kareiva, Mater. Res. Bull. 41 (2006) 1754.

[17] S.V. Dorozhkin, J. Mater. Sci. 42 (2007) 1061.

[18] P. Parhi, A. Ramanan, A.R. Ray, Mater. Lett. 58 (2004) 3610.

[19] Z. Yang, Y. Jiang, Y. Wang, L. Ma, F. Li, Mater. Lett. 58 (2004) 3586.

[20] C. Li-yun, Z. Chuan-bo, H. Jian-feng, Mater. Lett. 59 (2005) 1902.

[21] Q. He, Z. Huang, Y. Liu, W. Chen, T. Xu, Mater. Lett. 61 (2007) 141

[22] H.E. Lundager Madsen, F. Christensson, J. Cryst. Growth, 114 (1991) 613.

[23] S.H. Kwon, Y.K. Jun, S.H. Hong . H.E. Kim, J. Europ. Ceram. Soc. 23 (23) (2003) 1039.

[24] S. Hidaka, K. Abe, S.Y. Liu, Arch. Oral Biol. 36 (1991) 49

[25] C. Verwilghen, S. Rio, A. Nzihou, D. Gauthier, G. Flamant, P.J. Sharrock, J. Mater. Sci. 42 (15) (2007) 6062.

[26] J.K. Han, H.Y. Song, F. Saito, B.T. Lee, Mater. Chem. and Phys. 99 (2006) 235

[27] Y.-P. Lin, P.C. Singer, Geochim. Cosmochim. Acta. 70 (2006) 2530.

[28] K. Karageorgiou, M. Paschalis, G. Anastassakis, J. Hazard. Mat. 139 (2007) 447.

[29] P. Piantone, F. Bodénan, R. Derie, G. Depelsenaire, Waste Manag. 23 (B2) (2003) 22584.

[30] A.C. Tas, F. Aldinger, J. Mater. Sci. Mater. Med. 16 (2005) 167. 